http://dx.doi.org/10.6113/TKPE.2014.19.2.194

\title{
$\mathrm{DC}$ 마이크로그리드에서 에너지 저장장치를 위한 양방향 $\mathrm{DC}-\mathrm{DC}$ 컨버터의 무순단 절체 제어기법 \\ 권민호, ${ }^{1}$ 박준성 ${ }^{2}$, 최세완 ${ }^{\dagger}$
}

\section{A Seamless Transfer Method of Bidirectional DC-DC Converter for ESS in DC Micro-grids}

\author{
Min-Ho Kwon ${ }^{1}$, Jung-Sung Park $^{2}$, and Se-Wan $\mathrm{Choi}^{\dagger}$
}

\begin{abstract}
In DC micro-grid system energy storage systems (ESS) are responsible for storing energy and balancing power. Also, control target of the bidirectional DC-DC converter(BDC) for ESS should be changed depending on the operating mode. During the grid connected mode, the BDC controls the battery current or voltage. When a grid fault occurs, the BDC should change the control target to regulate the DC-bus. The BDC with conventional control method may experience large transient state during the mode change. This paper proposes a control method of BDC for ESS. The proposed control method is able to provide autonomous and seamless mode transfer by a variable current limiter. To validate the proposed concept, simulation results using PSIM and experimental results from a $2 \mathrm{~kW}$ prototype are provided.
\end{abstract}

Keywords: ESS, bi-directional dc-dc converter, dc micro-grid, autonomous control, seamless transfer

\section{1. 서 론}

중앙 집중식 방식의 대규모 화석연료의 발전을 줄이 고 신·재생에너지 사용의 확대를 위하여 지능형 전력망 (Smart-grid)이 대두됨에 따라 신·재생에너지를 기반으 로 하는 분산발전시스템에 대한 연구가 활발히 진행되 고 있다. 특히 도서·산간 지역의 분산발전시스템은 신. 재생에너지의 사용을 촉진시킬 뿐만 아니라 발전 설비 의 비용 부담을 크게 줄여준다 ${ }^{[1][2]}$.

분산발전 시스템에서 불규칙적으로 발전되는 신·재생 에너지를 전력 수요에 따라 효율적으로 운용하고 정전 또는 계통사고에 대비하여 독립적으로 전력망을 운용하 기 위해서 에너지 저장장치(Energy storage system : $\mathrm{ESS})$ 의 필요성이 증가하고 있는 추세이다 ${ }^{[3]}$.

Paper number: TKPE-2014-19-2-12

Print ISSN: 1229-2214 Online ISSN: 2288-6281

† Corresponding author: schoi@seoultech.ac.kr, Dept. of Electrical \& Information Eng., Seoul Nat'1 Univ. of Science and Technology

Tel: +82-2-970-6542 Fax: +82-2-972-2866

${ }^{1}$ Dept. of Electrical \& Information Eng., Seoul Nat'l Univ. of Science and Technology

${ }^{2}$ Dept. of New Energy Eng., Seoul Nat'l Univ. of Science and Technology

Manuscript received Dec. 26, 2013; accepted Feb. 21, 2014
소규모 전력망 중에서는 교류전원을 기준으로 연계되 는 교류 마이크로그리드(AC micro-grid) 시스템과 직류 전원을 기준으로 연계되는 직류 마이크로그리드 $(\mathrm{DC}$ micro - grid) 시스템으로 분류할 수 있다. 직류 마이크 로그리드 시스템은 교류 마이크로그리드 시스템과 달리 안정도, 주파수 동기화 및 무효전력 문제가 없을 뿐만 아니라 태양광, 풍력, 연료전지 같은 직류 발전 시스템 을 2 차 전력변환 없이 직류 부하에 공급이 가능한 장점

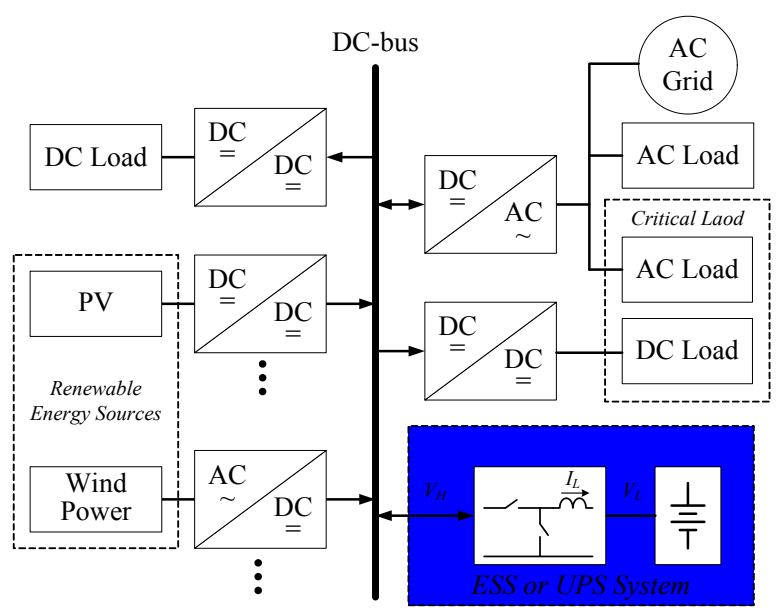

Fig. 1 A DC micro-grid system. 
이 있다 ${ }^{[4]}$.

그림 1 과 같은 직류 마이크로그리드 시스템에서 에너 지 저장장치는 잉여전력이 발생하거나 전력요금이 저렴 할 때 전력을 충전해놓고, 전력수요가 크거나 요금이 비 쌀 때 저장해놓은 전력을 부하에 공급하여 전력설비를 효율적으로 운용할 수 있게 하는 역할을 한다 ${ }^{[5][6]}$. 특히, 중요부하를 갖는 소규모 전력망의 경우 정전 또는 계통 사고가 있을 때 계통에 연계되어 있던 인버터가 DC-bus 전압을 제어하지 못하는 경우에는 에너지 저장 장치가 에너지원이 되어 $\mathrm{DC}-\mathrm{bus}$ 전압을 일정하게 유지 시켜주는 역할이 필요하다 ${ }^{[7][8]}$. 다시 말해서 에너지 저장 장치의 동작모드는 배터리 충.방전 양을 조절하여 전력 망의 전력관리를 하는 계통연계 모드와 DC-bus전압을 제어하는 독립운전 모드로 구분 할 수 있다. 에너지 저

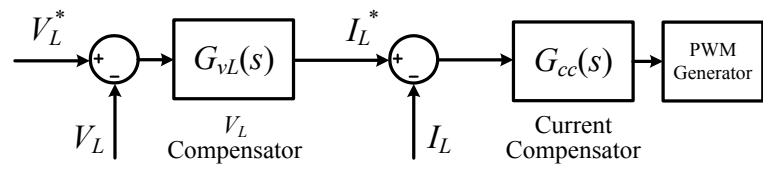

(a)

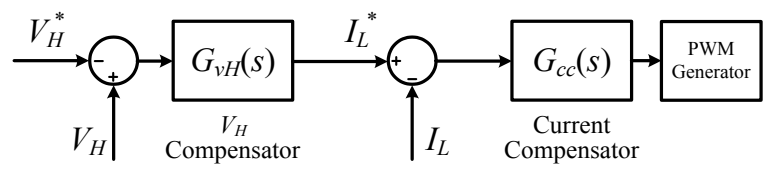

(b)

Fig. 2 Controllers for two operating modes (a) low side voltage controller for grid connected mode. (b) high side voltage controller for islanding mode

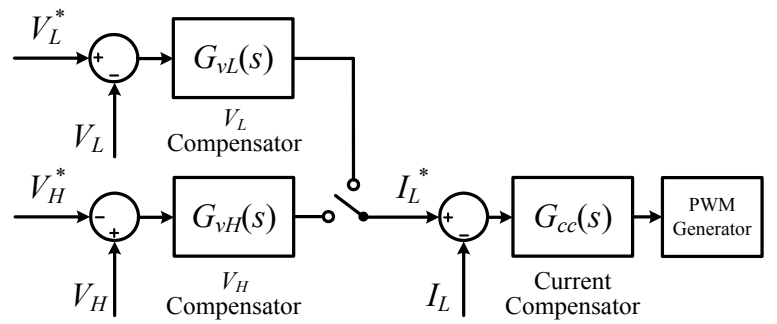

Fig. 3 Conventional control method for implementation of Fig. 2

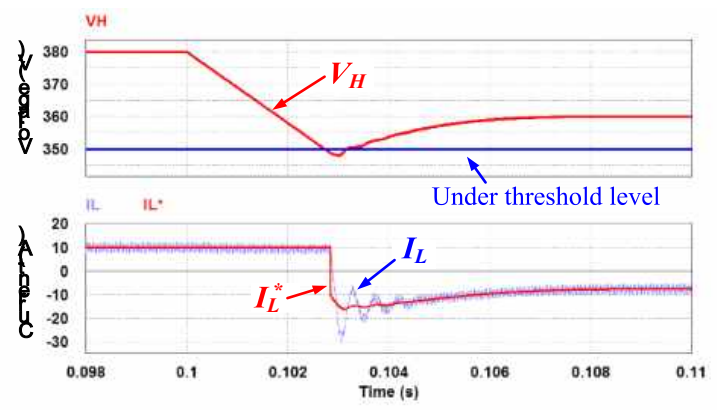

Fig. 4 Simulation waveform of the conventional mode transfer method
장장치는 신속하고 끊김없는 모드전환을 위해 상위제어 기의 지령 없이도 자율적인 판단으로 무순단절체 (Seamless transfer)가 가능한 양방향 DC-DC 컨버터가 요구된다 ${ }^{[9]}$.

에너지 저장장치용 양방향 $\mathrm{DC}-\mathrm{DC}$ 컨버터는 그림 2 (a)와 같이 계통연계 모드에서 배터리 전압 또는 전류를 제어하는 강압동작과 그림 2 (b)와 같이 독립운전 모드 에서 DC-bus전압을 제어하는 승압동작이 있으며 이는 상위제어기의 지령에 따라 선택적으로 변경될 수 있다. 그리고 컨버터가 동작 중에 모드를 전환하는 방법으로 는 그림 3 과 같이 전류 보상기를 공유하여 전류 지령치 를 선택적으로 변경하는 방식 ${ }^{[10]}$ 이 있는데 자율적인 판 단으로 모드전환을 이루기 위해서 일정 전압 범위를 벗 어났을 때 전압보상기를 절체하는 기법을 적용할 수 있 다. 하지만 이러한 방식은 비활성 보상기의 포화, 초기 오차 등으로 인하여 그림 4 와 같이 동작모드 전환 시 컨버터에 큰 과도상태 발생시킨다. 따라서 시스템의 안 정성이 저하되고 과도상태에서 소자들의 부담이 크게 증가 하게 된다.

본 논문에서는 자율적이며 입·출력 절환 시에도 전력 변환 동작이 끊임없는 제어 기법을 제안한다. 제안하는 제어기법을 통하여 신속한 모드전환이 가능한 에너지 저장장치 또는 무정전전원장치(Uninterruptible power supply : UPS)용 양방향 DC-DC 컨버터 개발로 소규모 전력망을 안정적으로 운용할 수 있게 한다.

\section{2. 제안하는 양방향 제어 기법}

\section{1 제어기의 구성}

제안하는 제어기의 기본 구조 ${ }^{[11]}$ 는 그림 5 와 같으며 일반적인 비례적분(Proportional-Integral)보상기를 이용

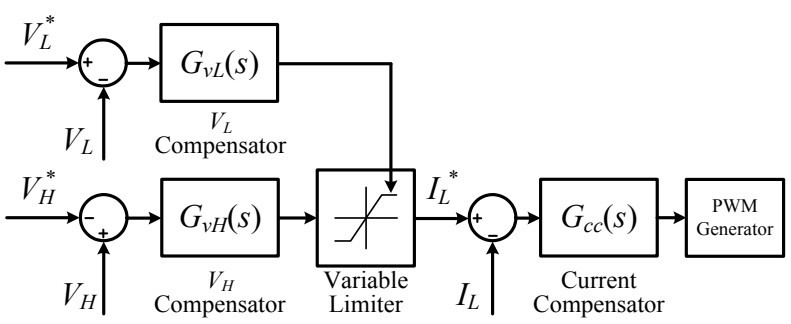

Fig. 5 Proposed control black diagram ${ }^{[1]}$

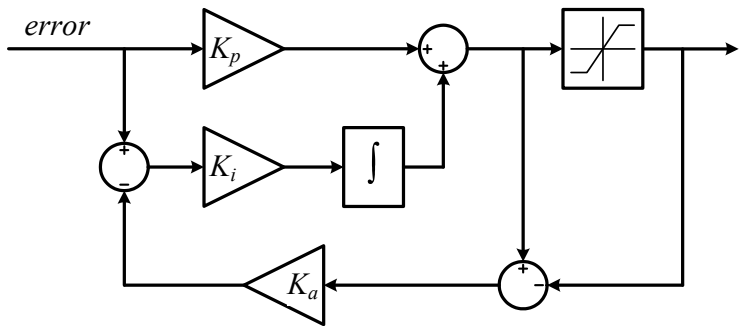

Fig. 6 PI compensator with anti-windup ${ }^{[12]}$ 
하여 평균 전류모드 제어(Average Current-mode Control)로 구현한 구조이다. 상한치가 변동 가능한 리 미터를 이용하여 고전압측 보상기와 저전압측 보상기를 하나로 통합한 구조로서 두 전압 보상기는 서로 상보적 으로 동작하게 된다.

계통연계 모드에서 고전압측 전압 지령치는 $\mathrm{DC}-\mathrm{bus}$ 의 정상 전압 보다 약간 낮게 설정하여 고전압 보상기 를 포화시키면 전류 지령치는 리미터 상한치인 저전압 보상기의 출력에 의해 결정된다. 반대로 독립운전 모드 에서의 전류 지령지는 고전압 보상기의 출력에 의해서 결정되며 저전압 보상기는 전류 지령치에 아무런 영향 을 주지 못하고 포화된다. 제안하는 제어기에는 각 보상 기가 비활성 되어있을 때 내부의 적분기의 누적 오차를 제한하기 위하여 안티와인드업(Anti windup) ${ }^{[12]}$ 이 필요 하다. 안티와이드업을 포함한 PI 제어기의 구조는 그림 6 과 같이 구현 하였다.

\section{2 동작원리}

\subsection{1 계통연계 모드에서 독립운전 모드}

그림 7 은 계통연계 모드에서 컨버터 모드전환시의 주 요파형이며 그림 8 은 각 모드별 동작 상태이다.

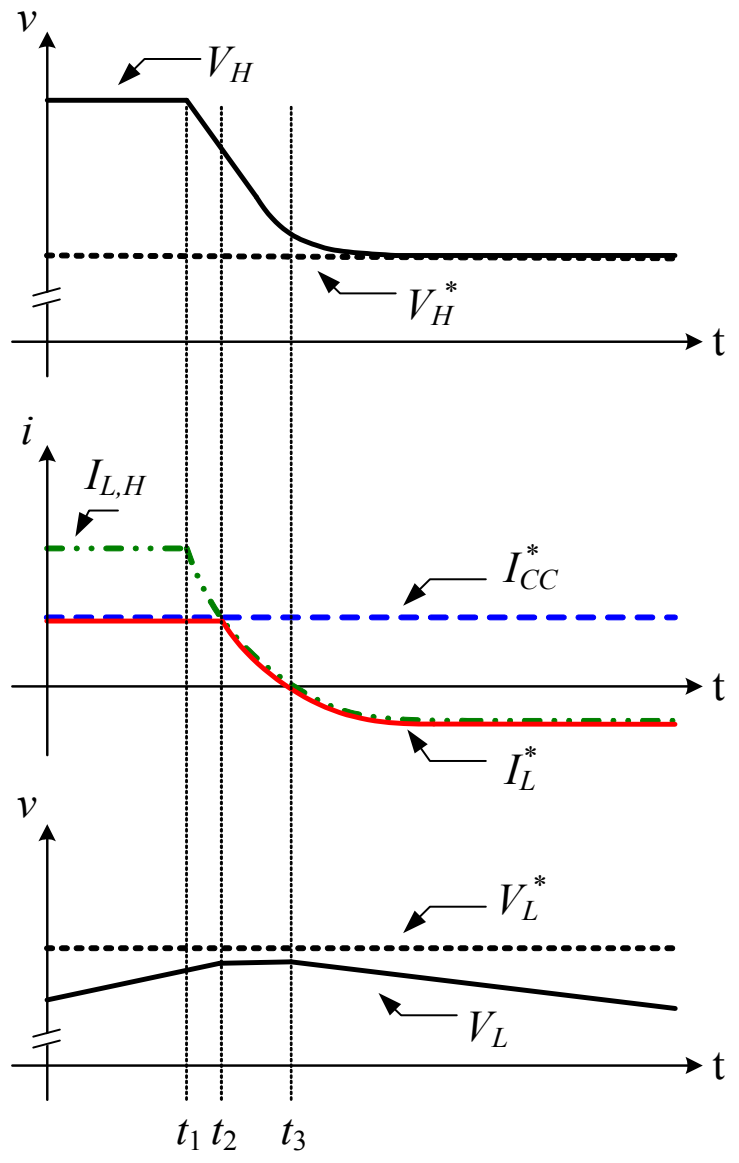

Fig. 7 Key waveforms of mode transfer from grid connected mode to islanding mode
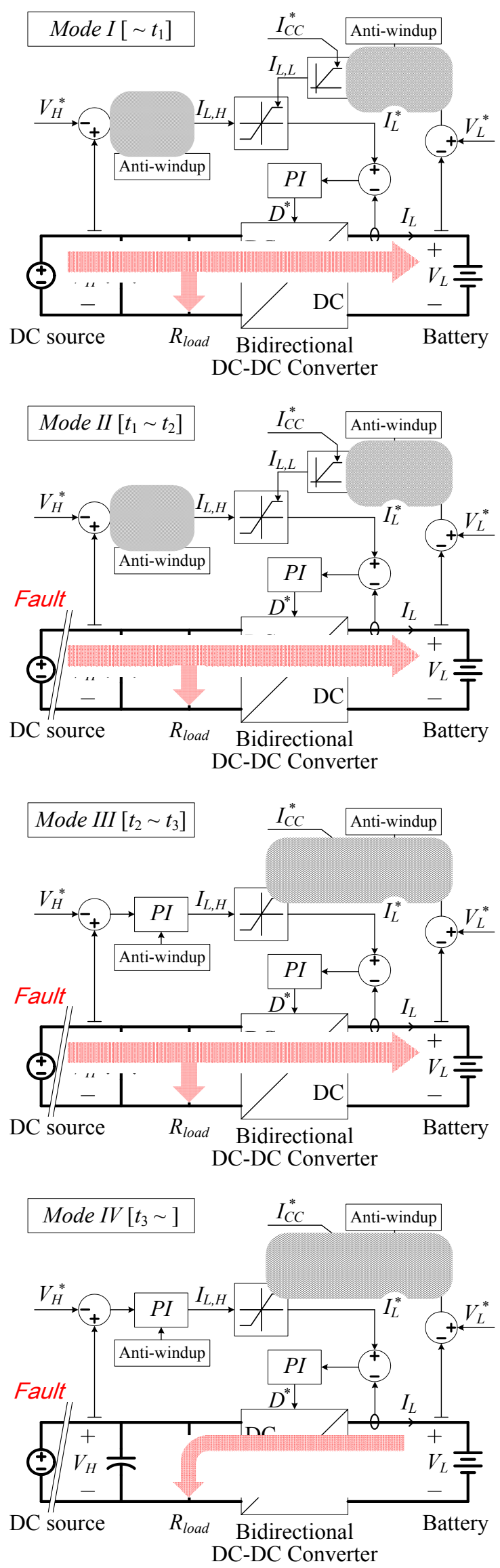

Fig. 8 Operating principle Mode I, II, III and $I V$ 
Mode $I\left[\sim t_{1}\right]: t$ 이전에 고전압측 전압원이 정 상동작하고 있고 고전압 보상기의 지령치 $\left(V^{*} H\right)$ 는 고전 압측 정상 전압보다 약간 낮은 값으로 설정한다. 그래서 고전압 보상기는 포화되어 있는 상태이고 배터리 전압 지령치 $\left(V^{*} L\right)$ 는 배터리의 최대 전압으로 설정하여 저전압 보상기 또한 포화된 상태이다. 결국 전류 보상기의 지령 지 $\left(I^{*} L\right)$ 는 저전압 보상기 출력의 리미터 상측값인 $I^{*} C C$ 에 의해서 결정되고 있다. 따라서 배터리는 양방향 컨버 터를 통해 일정 전류로 충전되고 있다.

Mode $I I\left[t_{1} \sim t_{2}\right]: t_{1}$ 에서 고전압측 전압원에 이상 이 발생되어 개방되면 고전압측 전압은 감소되기 시작 한다. 그러면 포화되어 있던 고전압 보상기의 오차 또한 감소하기 시작한다.

Mode $I I I\left[t_{2} \sim t_{3}\right]$ : 고전압 보상기의 출력이 $I^{*} C C$ 보다 작아지면 고전압 보상기는 활성화되어 고전압측 전압을 제어하기 시작하며 전류 지령치를 감소시킨다. 따라서 배터리의 충전전류 또한 감소한다.

Mode $I V\left[t_{3} \sim\right]$ : 고전압측 전압은 일정하게 유지 되고 전류 지령치는 음의 값이 되어 양방향 컨버터의 전류 방향이 바뀌어 배터리의 전력을 고전압측 부하로 전달한다.

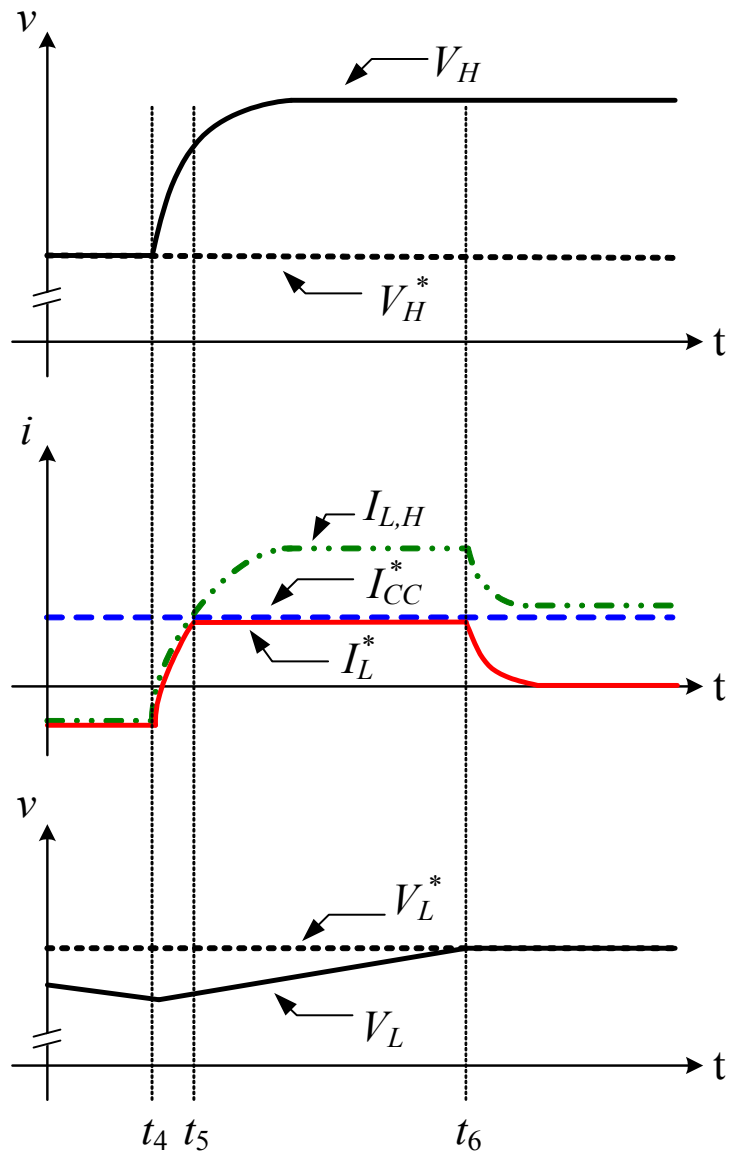

Fig. 9 Key waveforms of mode transfer from islanding mode to grid connected mode
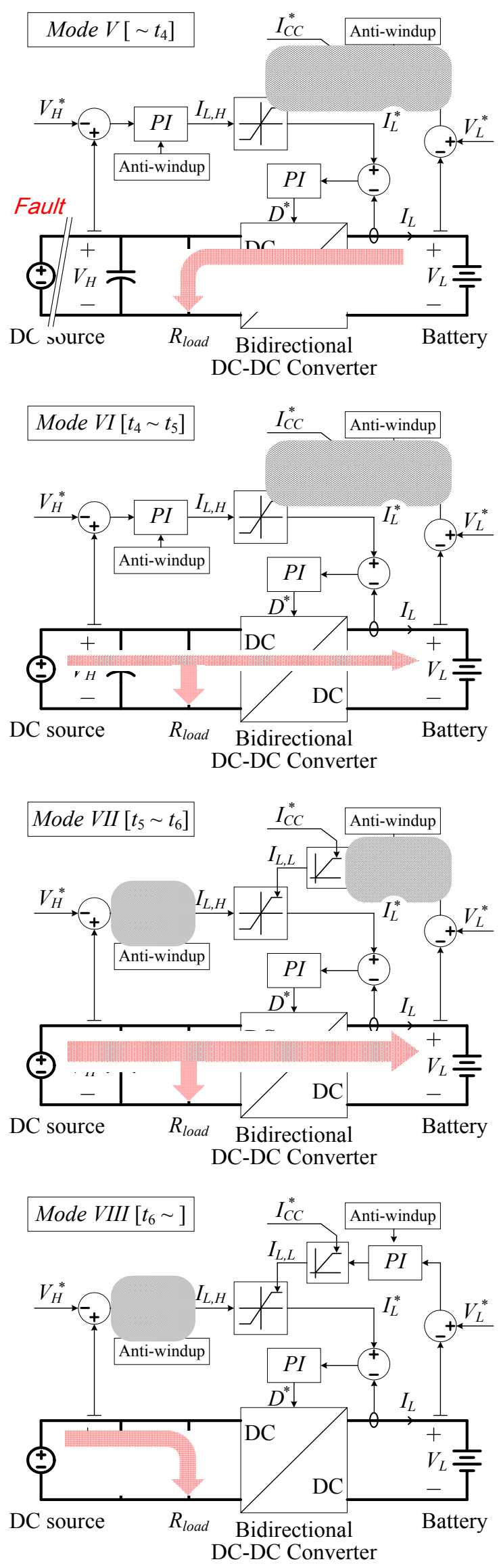

Fig. 10 Operating principle Mode V, VI, VII and VIII 


\subsection{2 독립운전 모드에서 계통연계 모드}

그림 9는 독립운전 모드에서 컨버터 모드전환시의 주 요파형이며 그림 10 은 각 모드별 동작 상태이다.

Mode $V\left[\sim t_{4}\right]$ : 이 모드에서 컨버터의 전류는 음 의 방향으로 배터리에서 고전압측 부하로 흐르고 있으 며 고전압측 전압은 양방향 컨버터에 의해 일정하게 유 지되고 있다. 배터리에서 전류를 내보내고 있기 때문에 배터리 전압은 감소하고 있고 배터리 전압 지령치보다 낮다. 따라서 저전압 보상기는 포화되어있다.

Mode VI [ $\left.t_{4} \sim t_{5}\right]: t_{4}$ 에서 고전압측에 개방되어 있던 전압원이 정상동작을 시작하여 고전압측 전압을 증가시키면 고전압 보상기의 출력이 증가하여 전류 지 령치가 증가하면 양방향 컨버터의 전류 방향이 바뀌게 된다.

Mode VII $\left[t_{5} \sim t_{6}\right]: t_{5}$ 에서 고전압 보상기의 출력 이 가변리미터의 상한치인 $I^{*} C C$ 보다 커지면서 고전압 보상기는 포화가 되기 시작하고 양방향 컨버터는 일정 전류(Constant current : $\mathrm{CC}$ )로 배터리를 충전시킨다.

Mode VIII [to ] : 증가하고 있는 배터리 전압이 저전압 지령치 까지 증가하면 포화되어 있던 저전압 보 상기는 활성화 되기 시작하며 충전 전류를 서서히 감소 시켜 일정 전압(Constant voltage : $\mathrm{CV}$ )으로 충전이 시 작된다.

\section{3. 시뮬레이션 및 실험 결과}

그림 11 과 같이 $2 \mathrm{~kW}$ 급 비절연 하프브릿지 컨버터를 이용하여 제안하는 제어 알고리즘을 검증 및 구현 하였 고 제어기는 TI社의 TMS320F28335를 이용하여 구현 되었다. 양방향 컨버터의 사양은 표 1 과 같다.

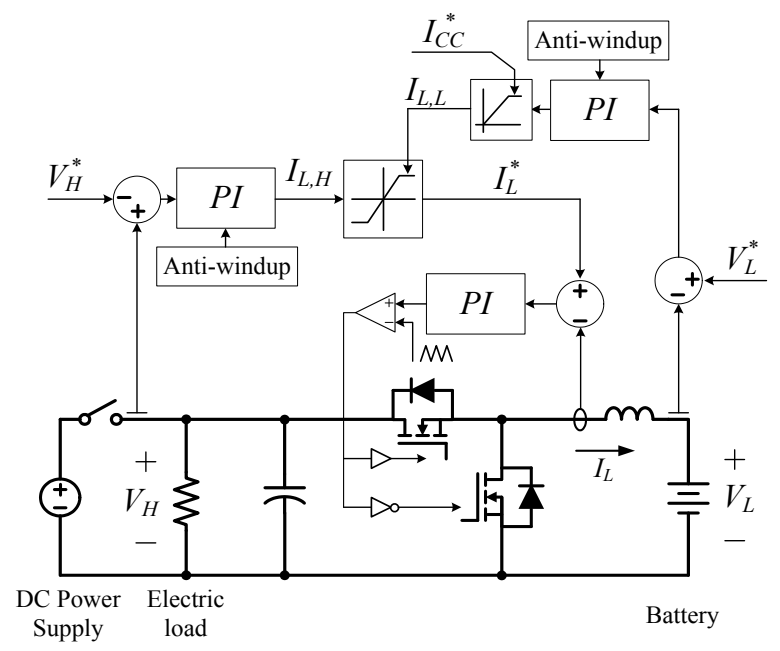

Fig. 11 Experimental construction and the proposed control system
Table 1 Parameters of the DC-DC converter

\begin{tabular}{l|c|c|c}
\hline \hline Parameter & Symbol & Value & Unit \\
\hline Power & $P$ & 2 & $\mathrm{~kW}$ \\
battery voltage & $V_{L}$ & $100 \sim 230$ & $\mathrm{~V}$ \\
DC-bus voltage & $V_{H}$ & $360 \sim 380$ & $\mathrm{~V}$ \\
Switching frequency & $f_{S}$ & 15 & $\mathrm{kHz}$ \\
\hline \hline
\end{tabular}
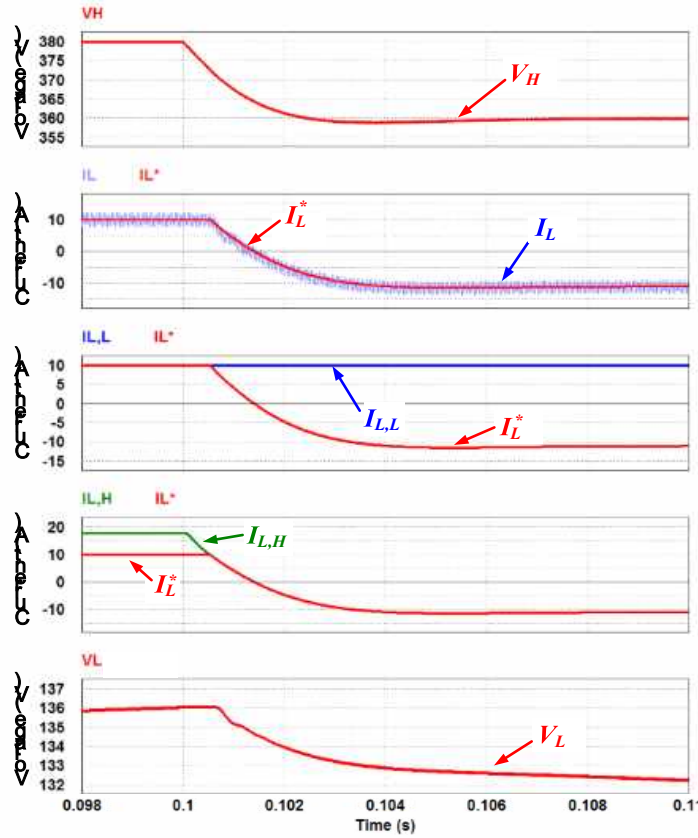

Fig. 12 Simulation results of mode transfer from grid connected mode to islanding mode
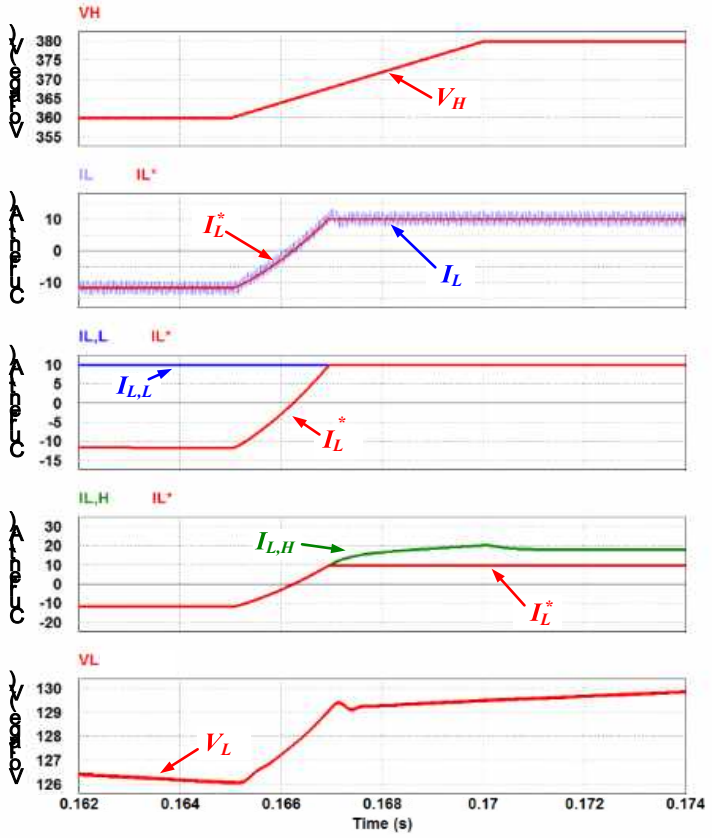

Fig. 13 Experimental waveforms of mode transfer from islanding mode to grid connected mode 


\section{1 시뮬레이션 결과}

그림 12 와 13 은 PSIM 시뮬레이션 결과 이다. 그림 12 는 고전압측에 $380 \mathrm{~V}$ 전압원이 있어 $10 \mathrm{~A}$ 로 배터리를 충 전하고 있던 중 고전압측 전압원을 개방시켰을 때의 컨 버터 주요 시뮬레이션 파형이다. 전류 지령치 $\left(I^{*} L\right)$ 는 저 전압 제어기의 출력 $(I L, L)$ 에 의해서 결정되어 지다가 고 전압측 전압원이 개방되어 $V_{H}$ 가 감소됨에 따라 고전압 제어기의 출력 $\left(I_{L, H}\right)$ 을 따라가게 된다. 따라서 고전압측 전압은 컨버터에 의해서 $360 \mathrm{~V}$ 로 제어되며 끊김없이 인 덕터 전류 방향이 바뀌는 것을 볼 수 있다. 저전압측 배 터리는 시뮬레이션 시간을 고려하여 적당히 큰 값의 캐 패시터와 저항을 직렬로 결선하여 진행 하였다. 그림 13 은 다시 고전압측 전압원이 단락된 후 다시 충전 모드 로 전환되는 시뮬레이션 파형이다. 고전압측 전압이 상 승됨에 따라 전류 지령치 $\left(I^{*} L\right)$ 는 제어기의 출력 $(I L, L)$ 으 로 결정되며 마찬가지로 끊김없이 전류 방향을 바꾸어 배터리에 일정전류로 충전을 시작한다.

\section{2 실험 결과}

그림 14 와 15 는 제안하는 제어 알고리즘의 실험결과 로서 모드전환 되는 순간에 고전압측 및 저전압측 전압 과 양방향 컨버터의 인덕터 전류파형을 보여준다. 그림 14 는 양방향 컨버터의 고전압측에 $380 \mathrm{~V}$ 직류전원공급 장치를 연결하여 저전압측 배터리에 $5 \mathrm{~A}$ 의 일정전류를 충전 중에 고전압측 직류전원공급 장치를 껐을 때 양방 향 컨버터가 자율적인 판단으로 전류 방향을 바꾸어 동 작하는 파형이며 모드전환의 과도상태가 작은 것을 볼 수 있다. 그림 15는 배터리가 방전 중에 다시 직류전원 공급 장치를 켰을 때의 실험파형으로 마찬가지로 자율 적이며 끊김없이 모드전환이 이루어지는 것을 확인 할 수 있다. 그림 16은 배터리 충전동작으로 일정 전류 모 드에서 일정 전압 모드로 전환되는 파형이다.

\section{4. 결 론}

본 논문에서는 $\mathrm{DC}$ 마이크로그리드를 위한 에너지 저 장장치용 양방향 $\mathrm{DC}-\mathrm{DC}$ 컨버터의 제어 기법을 제안하 였다. 제안하는 기법은 상위지령 없이 자율적으로 모드 전환이 가능하며 끊임없는 전류제어로 모드전환시 과도 상태를 크게 줄인다. PSIM을 이용한 모의실험과 $2 \mathrm{~kW}$ 급 시작품을 통한 실험 결과로 본 논문의 타당성을 입증 하였다.

이 연구는 서울과학기술대학교 교내 학술연구비 (일부)지원으로 수행되었습니다.

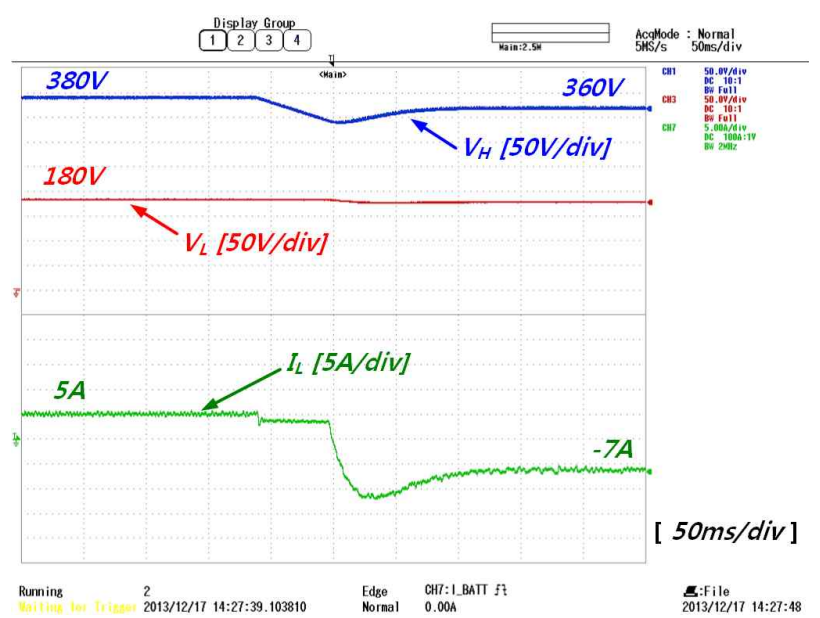

Fig. 14 Experimental waveforms of mode transfer from grid connected mode to islanding mode

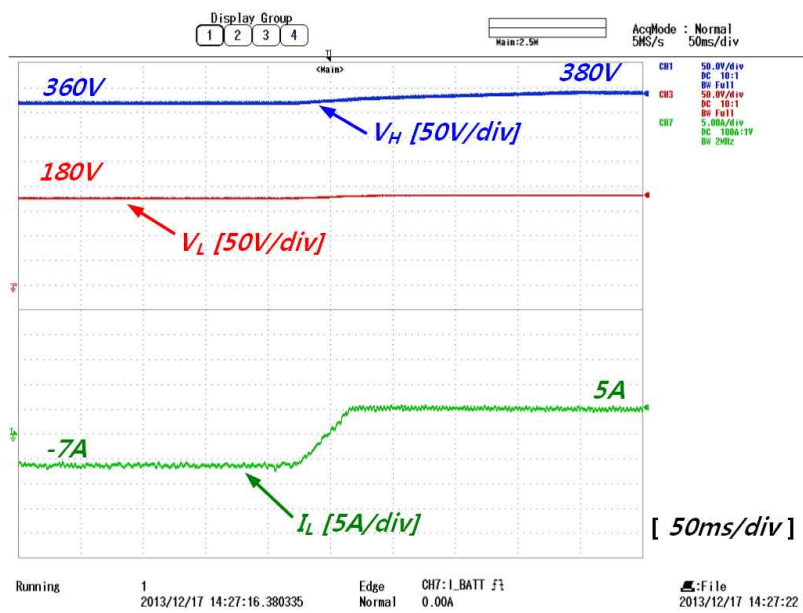

Fig. 15 Experimental waveforms of mode transfer from islanding mode to grid connected mode

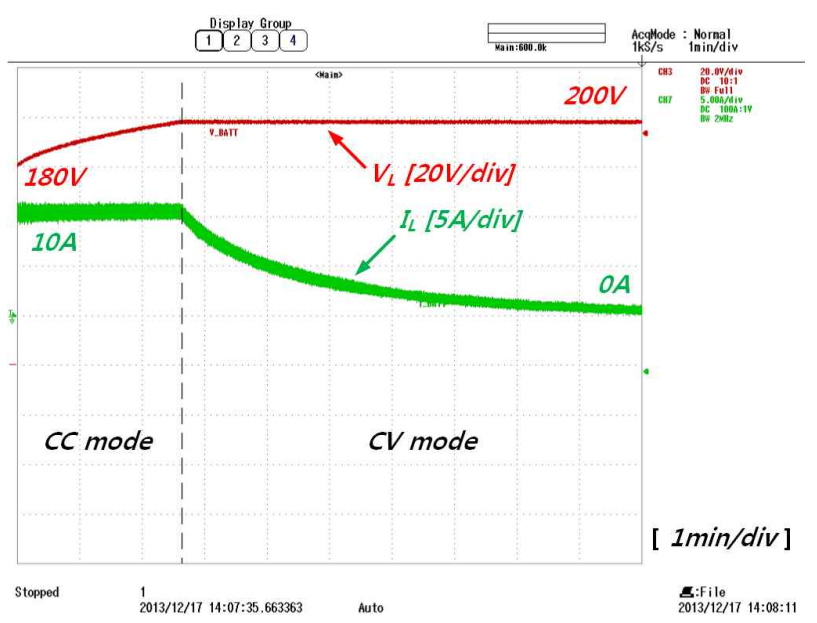

Fig. 16 Experimental waveforms of battery charging 


\section{References}

[1] P. Chiradeja and R. Ramakumar, "An approach to quantify the technical benefits of distributed generation," IEEE Trans. Energy Convers., vol. 19, no. 4, pp. 764-773, Dec. 2004.

[2] P. Chiradeja, "Benefit of distributed generation: A line loss reduction analysis," in Proc. Transmiss. Distrib. Conf Exhib., Asia. Pac., 2005, pp. 1.5.

[3] H. Zhou, T. Bhattacharya, D. Tran, T. S. T. Siew and A. M. Khambadkone, "Composite Energy Storage System Involving Battery and Ultracapacitor With Dynamic Energy Management in Microgrid Applications," IEEE Trans. Power Electron., Vol. 26, No. 3, pp. 923-930, Mar. 2011.

[4] J. Lee, H. Kim, B. Han, Y. Jeong, H. Yang and H. Cha, "DC Micro-Grid Operational Analysis with a Detailed Simulation Model for Distributed Generation," Journal of Power Electron., Vol. 11, No. 3, May 2011.

[5] H. Kakigano, Y. Miura, T. Ise, and R. Uchida, "DC micro-grid for super high quality distribution -system configuration and control of distributed generations and energy storage devices-," in Proc. IEEE Power Electron. Spec. Conf (PESC'06), pp. 1-7.

[6] K. Yukita, K. Ban, Y. Goto, K. Ichiyanagi, K. Hirose, T. Ushirokawa, Y.Okui and H. Takabayashi, "Power Supply System of DC/AC Micro Grid System," in Proc. 8th Int. Conf. Power Electron, ECCE Asia, Jeju Korea, May 30 - Jun. 3, 2011, pp. 228-234.

[7] H. Kakigano, Y. Miura, and T. Ise, "Configuration and control of a DC microgrid for residential houses," in Proc. IEEE Transmis. Distrib. Conf Expo: Asia Pacific, Oct. 2009, pp. 1-4.

[8] K. Sun, L. Zhang, Y. Xing and J. Guerrero, "A distributed control strategy based on DC bus signaling for modular photovoltaic generation systems with battery energy storage," IEEE Trans. Power Electron, vol. 26, no. 10, pp. 3032-3045, Oct. 2011.

[9] T. Han, J. Lee, H. Kim and B. Han, "Optimized Design and Coordinated Control for Stand-alone DC Micro-grid," The Transactions of the Korean Institute of Power Electronics, Vol. 18, No. 1, Feb. 2013.

[10] X. she, S. Lukic and A. Q. Huang, "DC zonal micro-grid architecture and control," in Proc. IECON, 2010, pp. 2982-2987.

[11] S. Choi, J. Park, M. Kwon, "System for controlling bidirectional converter" Korean Patent pending 10-2013-0092123, Aug. 2. 2013.

[12] C. Bohn, and D. P. Atherton, "An analysis package comparing $\mathrm{PID}$ anti-windup strategies," IEEE Control Syst. Mag., vol. 15, no. 2, pp. 34-40, Apr. 1995.

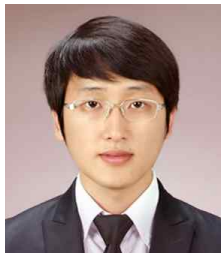

\section{권 민호(權民浩)}

1985년 8월 17일생. 2012년 서울과학기술대 제어계측공학과 졸업. 2014년 동 대학원 제 어계측공학과 졸업(석사). 2014년 현재 동 대학원 전기정보공학과 박사과정.

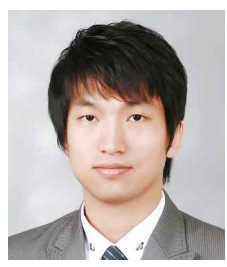

박준성 (朴峻成)

1982년 4월 26일생. 2009년 서울과학기술대 제어계측공학과 졸업. 2011년 동 대학 에너 지환경대학원 신에너지공학과 졸업(석사) 2011년 현재 동 대학원 박사과정.

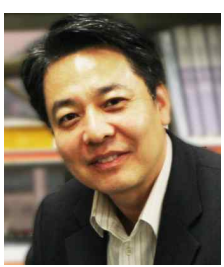

최세완(崔世琓)

1963년 3월 3일생. 1985년 인하대 전자공학과 졸업. 1992년 Texas A\&M Univ. 대학원 전기 공학과 졸업(석사). 1995년 동 대학원 졸업(공 박). 1985년 1990년 대우중공업 중앙연구소 대리. 1996년 1997년 삼성전기 종합 연구소 수석연구원. 1997년 현재 서울과학기술대 전기정보공학과 교수. 당 학회 국제이사. 